\title{
Determination of the median lethal concentration of 'Omo' and 'Ariel' on Clarias gariepinus
}

\author{
Gambari Uthman Olatunji Bola \\ Department of Science Laboratory, Delta State Polytechnic Ozoro, Nigeria \\ E-mail; u.gambari@gmail.com \\ Accepted 13 July, 2016
}

\begin{abstract}
The median lethal concentration of two detergents; "Omo" and "Ariel" on Clarias gariepinus (Catfish) were determined by comparing their behavioural responses after being exposed to these detergents at acute concentrations and to the control (without detergents).Juvenile of the African Catfish Clarias gariepinus mixed sex and the same broad stock mean weight and length $(10.76 \pm 0.4 \mathrm{~g})$ and $(10.50 \pm 0.32 \mathrm{~cm})$ respectively. Obtained from fishpond, and treated in vitro in large in large plastic aquaria of $50 \mathrm{~L}$ capacity with well aerated borehole water. Acclimatized for $\mathbf{1 0}$ days, fed with commercial pellet food and later transferred to the experimental plastic aquaria. 10 fish per 20Laquarium. Concentrations of $0.05,0.07,0.09,0.1$ and $0.15 \mathrm{~g} / \mathrm{L}$ detergents were prepared and introduced into the five plastic tanks in replicate of equal dimension and under the same environmental conditions. Ten (10) fingerlings of the fish were introduced in each tank while the control tank had no detergent. The behavior of the test Organisms were observed at 24, 4872 and 96 hours after the treatment. It was found that the detergents are acutely toxic to the experimental fish due to the shooting up of the media's $\mathrm{pH}$ to the alkaline death point. It is therefore recommended that water bodies should be made clean to avoid contamination killing aquatic organisms.
\end{abstract}

Keywords: Clarias gariepinus, Catfish, in vitro, lethal and acclimatized

\section{INTRODUCTION}

Toxicology is the study of the adverse effects of chemical or physical agents (Xenobiotic) on living organisms. These adverse effects may occur in many forms, ranging from immediate death to subtle change not realized until months or years later. It is recognized that virtually all toxic effects are caused by changes in specific cellular, molecules and biochemical. A Xenobiotic (foreigner) in small amounts may be nontoxic and even beneficial but when the dose is increased, toxic and lethal effects may result. Acute toxicity is the discernible adverse effects induced in organism within a short period of time (days) of exposure in water for a period of up to four (4) days. It is now known that various observable changes in anatomy or body functions actually result from previously unrecognized changes in specific biochemical in the body. Waste water discharged from industrial operations is among the worst sources of water pollution because of their high Biochemical Oxygen Demand (BOD). These waste waters may contain high concentration of toxicants which of discharged untreated could kill virtually all aquatic organism in the vicinity of the out falls. Among ecological toxicants, synthetic detergents released into the aquatic ecosystem with a potential effect on the floral and fauna are of paramount importance. Household detergents have been known to contain traces elements such as manganese, chromium, nickel, cobalt, zinc, stratum and boron (Ajao, 1990). The use of detergents in houses and factories may result in contamination / pollution of aquatic ecosystem. This problem arises from the fact that a large part of sewage these days consists of synthetic detergents (anionic and cationic) which are used in most household in washing, scrubbing and cleaning.

The term 'detergent' is applied to a wide variety of 
cleaning materials used to remove dirt's or stains from clothes, dishes, and a lot of other things. Synthetic detergents were first used in the 1930s, but it was not until 1960s and later that they became popular with large quantities entering aquatic ecosystem as sewage through drainage (Imonite, 1994). Before the advent of detergent, soap was used for household chores. With the introduction of synthetic detergents, household chores became easier and marketing was more successful as their detergents superseded soap as water softeners and prevented scum in hard water. However, the ready availability of detergents such as 'Omo', 'Ariel' etc and their extensive use for both domestic and industrial purposes have necessitated this research on their effect on aquatic resources particularly fish.

The African catfish Clarias gariepinus is an ecologically important and commercial valued fish for the Nigeria fishing industry (Ita, 1980). They are frequently and widely cultured in ponds as they also occur freely in Nigerian Natural Fresh water. Clarias gariepinus was chosen for this study because they constitute one of the main fish foods of economic value as food in Nigeria. They are popular with fish farmers and consumers thus it's importance for the sustainability of Aquaculture industry. Clarias gariepinus has been chosen for this study because they constitute one of the main fish foods of economic value as food in Nigeria. They are popular with fish farmers and consumers and therefore important for the sustainability of aquaculture in industry.

\section{AIM OF STUDY}

This study is conducted to determine the median lethal concentration of 'Omo' and 'Ariel' on Clarias gariepinus after the 24, 48, 72 and 96 hours exposure period and to compare the behavioral responses of experimental fish exposed to these detergents at acute concentrations to the control. The selection of the detergent product was based on their market share by volume, as the two detergents chosen comprise nearly $50 \%$ of the market.Detergents are organic compounds, which have both polar and non-polar characteristics. They tend to exist at phase boundaries, where they are associated with both polar and non-polar media. Detergents are of three types: anionic, cationic, and non-ionic. Anionic and cationic have permanent negative or positive charges, attached to non-polar (hydrophobic) C-C chains. Non-ionic detergents have no such permanent charge; instead, they have a number of atoms which are weakly electropositive and electronegative. This is due to the electron-attracting power of oxygen atoms. Detergents are common household and industrial products and their role as polluting agents of natural water cannot be ignored. The validity of a detergent as a toxicant depends on three factors - response of the test animal, the substances mode of action and toxicity of the toxicant in relation to its chemical and physical structure.

There are two kinds of detergents with different characteristics: phosphate detergents and surfactant detergents. Detergents that contain phosphates are highly caustic, and surfactant detergents are very toxic. The differences are that surfactant detergents are used to enhance the wetting, foaming, dispersing and emulsifying properties of detergents. Phosphate detergents are used in detergents to soften hard water and help suspend dirt in water. Some detergents are persistent/ 'hard' and causes river to foam. Such foamy water is harmful to adequate and human health. These 'detergents swan' have been reported to reduce the uptake of Oxygen considerably in as little as $1.0 \mathrm{ppm}$ of these substances dissolved in water. In general, detergents that are soft/biodegradable are chemically unstable/non-persistent. The non-persistent ingredients can be easily broken down by micro organism giving rise to plant nutrients such as nitrates and phosphate. Active detergents are resistant to decomposition by bacterial action during sewage treatment. The presence of excess plant nutrient in form of nitrates and phosphates, a phenomenon known as eutrophication in aquatic habitat can lead to excess growth of plant. Monitoring of anionic and non-ionic surfactants dispersed in aquatic environment has indicated that surfactants may be present at concentrations that are known to cause acute or chronic effect on sensitive species of fish (Madson et al., 1996). Detergents are among the most important pollutants of the aquatic environment. Although many studies have been conducted on the toxicity of surfactants on aquatic organism, little is known about the impact of detergents as complex chemical mixtures. In a study done by Conti, (1987) the acute toxicity of three detergents on the lugworm (Arenicola marina) exhibited 48-hour $\mathrm{LC}_{50}$ values from 12 to $15 \mathrm{mg} / \mathrm{L}$. In another experiment done by Lal, et al., (1984) using the water flea (Daphnia magna), median tolerance limits for a synthetic detergent was recorded at $0.013 \mathrm{mg} / \mathrm{L}$. the rate of survival of the organism decreased with increasing concentration and time in a close dependent response. The rate of entry of detergents across gills will almost certainly be affected by the ventilation of the external surface of the gill lamella and it is dependent on factors such as environmental divalentin concentration. Therefore, the addition of detergent to external bathing solution introduces two variables: the rate of detergent entering and its action on gill cells.(Imonite, 1994). reported that detergents have been formed to impair respiration and salt balance in fish. They also show that non-lethal concentrations of alkyl-sulphonate damage the gills of the fish Lepomis gibbosus after 24hours 
exposure and reported that acute toxicity test carried out with branched chain sodium alkyl benzene sulphonate- a biodegradable, soft detergent, indicated that both agents damage the Ictalurus natalis which were exposed to concentration as low as $0.5 \mathrm{ppm}$. Okoli-Anunobi et al., (2002) reported that fish displays respiratory distress in toxic concentration of synthetic detergents / soaps does not appear to have created any major fish toxicity problem.

In the study of acute toxicity of industrial detergent corrosion inhibitor (Norust CR486) on the cichlids: Tilapia guineensis conducted by Ezemonye et al., (1997) showed that the 96 hours $\mathrm{LC}_{50}$ was $5.30 \mathrm{mg} / \mathrm{L}$. Okoli-Anunobi et al., (2002) studied the lethal effects of detergent (Elephant Blue detergent) on Oreochromis niloticus using a continuous flow toxicant auto-delivery system and reported the $96 \mathrm{~h} \mathrm{LC}_{50}$ as $9.77 \mathrm{mg} / \mathrm{L}$. Other research work on discharge in water bodies have been reported by several authors, Chindah et al., (2004) reported the acute toxicity of an organophosphate pesticide (chloropyrifos) on the juvenile of Tilapia guineansis was evaluated to determine its effect on the survival and body functions. The fish was exposed to varying levels of the toxicant $(0.0125,0.025,0.05$ and $0.1 \mathrm{mgl}^{-1}$ ) using 96 hours static bioassay to determine the media lethal concentration (MLC) and median lethal time (MLT) for the different concentrations. The mortality was found to increase with $0.002 \mathrm{mg} / \mathrm{L}$ while the 96 hours MLC was $0.002 \mathrm{mg} / \mathrm{L}$ while the 96 hours MLT of 56.2 hours, 42.7 hours, 31.1 hours and 18.2 hours were recorded for $0.0125 \mathrm{mg} / \mathrm{L}, 0.05 \mathrm{mg} / \mathrm{L}$ and $0.1 \mathrm{mg} / \mathrm{L}$ respectively. The operculum beat frequency $(F=$ cal6.89> $P=3.49) 0.05$ and Tail beat frequency $(\mathrm{F}=\mathrm{cal} 4.46 \mathrm{P}=3.49) 0.05$ were significantly affected by the exposure.

A prepared solution of cassava leaf extract was used to test the toxicity of cassava leaf on the fingerlings of Clarias angiullaria, five graded concentrations of 100 , $80,60,40$ and $20 \%$ and a control - represented by tanks 1, 2, 3, 4, 5 and 6 were reported by Aguigwo, (1998). He reported mortalities in tank 1, 2 and 3 after 96 hours and later in tank 4 after 120th hours only. A bioassay test performed on the toxic effect of cassava mill effluent to the African catfish Heteroclarias- hybrid of Heterobranchus bidorsalis (male) and Clarias gariepinus (female). However, the 96 hours $\mathrm{LC}_{50}$ was determined as $50.12 \mathrm{mgl}^{-1}$ by Oti, (2002). He also reported that exposed fish became darker in colour and showed signs of respiratory distress, increased opercular movement were observed before death occurred.

Acute toxicity test were carried out with aqueous and ethanolic extracts of two botanicals on Clarias gariepinus juveniles 96 hours LC $_{50}$ values for Parkia biglobosa aqueous (AEPB) and ethanolic extracts (EEPB) were 2.8 and $2.4 \mathrm{ppm}$ respectively while for Raphia vinifera aqueous (AERV) and ethanolic extracts
(EERV), the values were 3.4 and $3.2 \mathrm{ppm}$ respectively. The resulting 96 hours $\mathrm{LC}_{50}$ values showed that the extracts of Parkia biglobosa were more potent than the extracts of Raphia vinifera and that EEPB was the most toxic. Histopathological changes in liver and gill of exposed fish showed subtle cellular damages like necrosis, lesion, oedema and hepatocytes (Fafoye, et al., 2004).

\section{MATERIALS AND METHODS}

\section{Experimental fish}

Juvenile of the African catfish Clarias gariepinus mixed sex and the same brood stock mean weight and length of $(10.76 \pm 0.48 \mathrm{~g})$ and $(10.50 \pm 0.32 \mathrm{~cm})$ respectively were obtained from Songhai Delta fish pond in Sapele, Delta State. The fish were held in the laboratory in large plastic aquaria of $50 \mathrm{~L}$ capacity with well aerated borehole water. The fish were acclimatized for 10 days and were feed with commercially pellet feed (copens $2.0 \mathrm{~mm})$. They were then transferred to the experimental plastic aquaria, Ten (10) fish per $20 \mathrm{~L}$ aquarium.

\section{Test solution}

The toxicants used were synthetic detergents commonly called 'Ariel' and 'Omo'. These detergents were in powdered form. A stock solution of each detergent was prepared by dissolving $1 \mathrm{gm}$ of the detergent in $1 \mathrm{~L}$ of de-chlorinated water. From the stock solution serial dilutions method (Warner, 1962) was made to obtain concentration of $0.05,0.07,0.09,0.1$ and $0.15 \mathrm{~g} / \mathrm{L}$ detergents.

\section{Bioassay procedure}

Twenty (20) litres aquaria were maintained throughout the exposure period. Ten (10) juvenile each were placed in the $20 \mathrm{~L}$ plastic aquarium. Well aerated borehole water was used during acclimatization. Feeding was done twice daily (0800 and 1800 hours) with the diet during acclimatization period but stop prior to exposure. In order to monitor the toxicant strength, level of dissolved oxygen, the effects of evaporation, ammonia concentration during experimentation the entire test water and concentration of toxicant in each aquarium was renewed 24 hours interval. The exposure period lasted for 4 days during which some water quality parameters were monitored after 24hours using method described by APHA, (1989). The water quality parameters monitored include the following: temperature, dissolved oxygen, free carbon (iv) oxide, alkalinity and hydrogen ion concentration. The five 
graded concentrations were prepared and introduced in five plastic tanks in replicate of equal dimension and under the same environmental conditions. Ten (10) fingerlings of Clarias gariepinus were introduced in each tank. The sixth similar tank which contained 10 fingerlings had no detergent and so served as the control. The behaviour of the test organisms like swimming activity- opercular beats and death were observed at 24, 48, 72 and 96 hours after the introduction of the fish into the test solution.

\section{Water quality parameters}

The water quality parameters of the water with the malachite green toxicant bioassay were monitored every 24hours. The procedure for the determination of the water quality parameters were conducted according to APHA, (1989) as follows:

\section{Temperature}

The temperature was measured by dipping a dry bulb Celsius thermometer in about $10 \mathrm{~cm}$ below the water surface in each aquarium and allowed to equilibrate for 5 minutes before the reading was taken.

\section{Hydrogen ion concentration (ph)}

Ten $(10 \mathrm{~mL})$ water sample was drain into a beaker and reading was taken with Jenway model $\mathrm{pH}$ meter.

\section{Total alkalinity}

This involves phenolphthalein and methyl orange alkalinity:

\section{Phenolphthalein alkalinity}

In this, $100 \mathrm{ml}$ of water sample was drawn into a volumetric flask in which four (4) drops of phenolphthalein indicator was added. If the sample remains clear $0.0 \mathrm{mg} / \mathrm{L}$ was recorded, otherwise, it was titrated with $0.002 \mathrm{~N} \mathrm{H}_{2} \mathrm{SO}_{4}$ from a burette until it becomes clear. Phenolphthalein alkalinity $=10 \mathrm{X}$ volume of $0.02 \mathrm{~N} \mathrm{H}_{2} \mathrm{SO}_{4}$ used in $\mathrm{mg} / \mathrm{L}$ of $\mathrm{CaCO}_{3}$.

\section{Methyl orange alkalinity}

This involves measuring $100 \mathrm{ml}$ of water sample into volumetric flask and adding 3 drops of methyl orange indicator. The sample was then titrated with $0.02 \mathrm{NH}_{2} \mathrm{SO}_{4}$ till the greenish yellow colour turns pink orange. Methyl orange Alkalinity $=10 \mathrm{X}$ volume of $0.02 \mathrm{NH}_{2} \mathrm{SO}_{4}$ used in $\mathrm{mg} / \mathrm{L}$ of $\mathrm{CaCO}_{3}$. Total Alkalinity = Phenolphthalein Alkalinity + Methyl orange Alkalinity

\section{Dissolved oxygen}

$250 \mathrm{ml}$ of water sample was collected into $250 \mathrm{ml}$ reagent bottle. Air bubble was avoided during collection. $2 \mathrm{ml}$ of manganous sulphate followed by $2 \mathrm{ml}$ of alkaline iodide sodium azide solution were added to the water sample in reagent bottle. The bottle was covered and inverted vigorously a few times to ensure thorough mixing of the reagent with the water sample. The flocculent was allowed to settle to about $1 / 3$ of the volume of the bottle after which the stopper was removed and $2 \mathrm{ml}$ of concentrated tetra-oxo-sulphate (vi) acid $\left(\mathrm{H}_{2} \mathrm{SO}_{4}\right)$ was carefully added. The bottle was covered gently to avoid air bubbles and vigorously inverted until the precipitate dissolved leaving yellow colour of free iodine. $200 \mathrm{ml}$ of the sample was then transferred into a conical flask and $2 \mathrm{~mL}$ of starch solution was added to the sample. The blue black coloured sample was titrated with $0.25 \mathrm{~N}$ sodium thiosulphate until the sample becomes colourless. The dissolved oxygen content was then determined.

\section{Free carbon (iv) oxide}

$100 \mathrm{ml}$ water sample was drawn into a conical flask to which 10 drops of phenolphthalein indicator was added. If sample turns pink $0.0 \mathrm{mg} / \mathrm{L}$ was recorded otherwise it was titrated with $\mathrm{N} / 44 \mathrm{NaOH}$ to achieve a weak pink colour. Free $\mathrm{CO}_{2}$ in $\mathrm{CaCO}_{3}=10 \times$ Volume of $\mathrm{N} / 44$ $\mathrm{NaOH}$ used

\section{Visual examination}

This was conducted on the behavioural pattern of the fish which include the erratic movement, leaping and instability. Also the organs such as eyes, fins, liver, gill and kidney of the sacrificed fish were observed.

\section{DATA ANALYSES}

The result obtain were analyzed with the use of prism graph pad version 5.0. Logarithm and arithmetic graph method according to Finney (1971) was used to determine the median lethal concentration of the detergents during the determined hours of exposed while the confidence limit was determined to know the 
032 E3 J. Sci. Res.

Table 1a: Cumulative Mean\# Mortality of Clarias gariepinus exposed to acute concentrations of Omo during the 96 hours exposure period

\begin{tabular}{lccccc}
\hline $\begin{array}{l}\text { Concentrations of } \\
\text { Omo (g/L) }\end{array}$ & $\begin{array}{c}\text { Mean number of } \\
\text { juveniles }\end{array}$ & \multicolumn{4}{c}{ Exposure period (Hours) } \\
\cline { 3 - 5 } & 10 & $\mathbf{2 4}$ & $\mathbf{4 8}$ & $\mathbf{7 2}$ & $\mathbf{9 6}$ \\
\hline 0.15 & 10 & 4.50 & 9.50 & 10.00 & 10.00 \\
0.10 & 10 & 3.00 & 6.50 & 9.50 & 10.00 \\
0.09 & 10 & 0.00 & 5.50 & 8.50 & 10.00 \\
0.07 & 10 & 0.00 & 2.50 & 4.00 & 6.50 \\
0.05 & 10 & 0.00 & 0.00 & 3.50 & 6.00 \\
0.00 (control) & & & & 0.00 & 0.00 \\
\hline
\end{tabular}

\# obtained from replicate exposure.

Table 1b: Cumulative Mean\# Mortality of Clarias gariepinus exposed to acute concentrations of Ariel during the 96 hours exposure period

\begin{tabular}{lccccc}
\hline $\begin{array}{l}\text { Concentrations of } \\
\text { Ariel (g/L) }\end{array}$ & $\begin{array}{c}\text { Mean number of } \\
\text { juveniles }\end{array}$ & \multicolumn{4}{c}{ Exposure period (Hours) } \\
\cline { 3 - 5 } & 10 & $\mathbf{2 4}$ & $\mathbf{4 8}$ & $\mathbf{7 2}$ & $\mathbf{9 6}$ \\
\hline 0.15 & 10 & 5.50 & 9.50 & 10.00 & 10.00 \\
0.10 & 10 & 3.50 & 7.00 & 9.50 & 9.50 \\
0.09 & 10 & 0.00 & 4.50 & 6.00 & 6.50 \\
0.07 & 10 & 0.00 & 2.00 & 3.00 & 4.50 \\
0.05 & 10 & 0.00 & 1.00 & 2.50 & 3.00 \\
0.00 (control) & & & & 0.00 & 0.00 \\
\hline
\end{tabular}

\# obtained from replicate exposure.

Table 1c: Logarithm Concentration, Mean Total Mortality and Probit Mortality of Clarias gariepinus exposed to acute Concentrations of Omo after 24, 48, 72 and 96 hours exposure periods respectively

\begin{tabular}{lccccccccc}
\hline $\begin{array}{l}\text { Concentration } \\
\text { Omo (g/L) }\end{array}$ & Log. Concentration & \multicolumn{3}{c}{ Mean Total Mortality (\%) } & \multicolumn{4}{c}{ Probit Mortality } \\
\cline { 2 - 10 } & & $\mathbf{2 4}$ & $\mathbf{4 8}$ & $\mathbf{7 2}$ & $\mathbf{9 6}$ & $\mathbf{2 4}$ & $\mathbf{4 8}$ & $\mathbf{7 2}$ & $\mathbf{9 6}$ \\
\hline 0.15 & -0.8239 & 75.0 & 95.0 & 100.0 & 100.0 & 5.67 & 6.65 & 8.72 & 8.72 \\
0.10 & -1.0000 & 45.0 & 65.0 & 95.0 & 100.0 & 4.87 & 5.38 & 6.65 & 8.72 \\
0.09 & -1.0458 & 30.0 & 55.0 & 85.0 & 100.0 & 4.48 & 5.13 & 6.04 & 8.72 \\
0.07 & -1.1549 & 0.0 & 25.0 & 40.0 & 65.0 & 0.00 & 4.33 & 4.75 & 5.38 \\
0.05 & -1.3010 & 0.0 & 25.0 & 35.0 & 60.0 & 0.00 & 4.33 & 4.62 & 5.25 \\
0.00 & - & 0.0 & 0.0 & 0.0 & 0.0 & 0.00 & 0.00 & 0.00 & 0.00 \\
\hline
\end{tabular}

limit of the toxicant efficacy. The one-way Analysis of variance (ANOVA) at $5 \%$ probability level was used to test for significant difference between various water quality parameters monitored.

\section{RESULTS}

\section{Acute toxicity}

Acute toxicity test of Clarias gariepinus exposed to acute concentrations $(0.00,0.05,0.07,0.09,0.1$ and $0.15 \mathrm{~g} / \mathrm{L}$ ) of 'Ariel' and 'Omo' during the 96 hours exposure period revealed 100 percent mortalities in $0.15 \mathrm{~g} / \mathrm{L}$ and $0.09, \quad 0.1, \quad 0.15 \mathrm{~g} / \mathrm{L}$ concentrations respectively during the 96 hours exposure. A positive correlation indicated by the linear relationship in this graph of logarithmic concentration versus probit mortality signifies that as concentration of toxicant increased mortality rate also increased. The rates of mortalities observed were directly proportional $(P<$ $0.05)$ to the detergents concentrations used. However, no mortality was recorded in the control exposure as represented in Table 1a and b. Table 1c and d illustrate the logarithm concentration, total mortality and probit mortality used for further analyses. 
TABLE 1d: Logarithm Concentration, Mean Total Mortality and Probit Mortality of Clarias gariepinus exposed to acute Concentrations of Ariel after 24, 48, 72 and 96 hours exposure periods respectively

\begin{tabular}{|c|c|c|c|c|c|c|c|c|c|c|}
\hline \multirow{2}{*}{$\begin{array}{l}\text { Concentration } \\
(\mathrm{g} / \mathrm{L})\end{array}$} & \multirow[t]{2}{*}{ Ariel } & \multirow[t]{2}{*}{ Log. Concentration } & \multicolumn{4}{|c|}{ Mean Total Mortality (\%) } & \multicolumn{4}{|c|}{ Probit Mortality } \\
\hline & & & 24 & 48 & 72 & 96 & 24 & 48 & 72 & 96 \\
\hline 0.15 & & -0.8239 & 75.0 & 95.0 & 100.0 & 100.0 & 5.67 & 6.65 & 8.72 & 8.72 \\
\hline 0.10 & & -1.0000 & 50.0 & 70.0 & 95.0 & 95.0 & 5.00 & 5.52 & 6.65 & 6.65 \\
\hline 0.09 & & -1.0458 & 35.0 & 45.0 & 60.0 & 65.0 & 4.62 & 4.87 & 5.25 & 5.38 \\
\hline 0.07 & & -1.1549 & 0.0 & 20.0 & 30.0 & 45.0 & 0.00 & 4.16 & 4.48 & 4.87 \\
\hline 0.05 & & -1.3010 & 0.0 & 10.0 & 25.0 & 30.0 & 0.00 & 3.72 & 4.33 & 4.48 \\
\hline 0.00 & & - & 0.0 & 0.00 & 0.0 & 0.0 & 0.00 & 0.00 & 0.00 & 0.00 \\
\hline
\end{tabular}

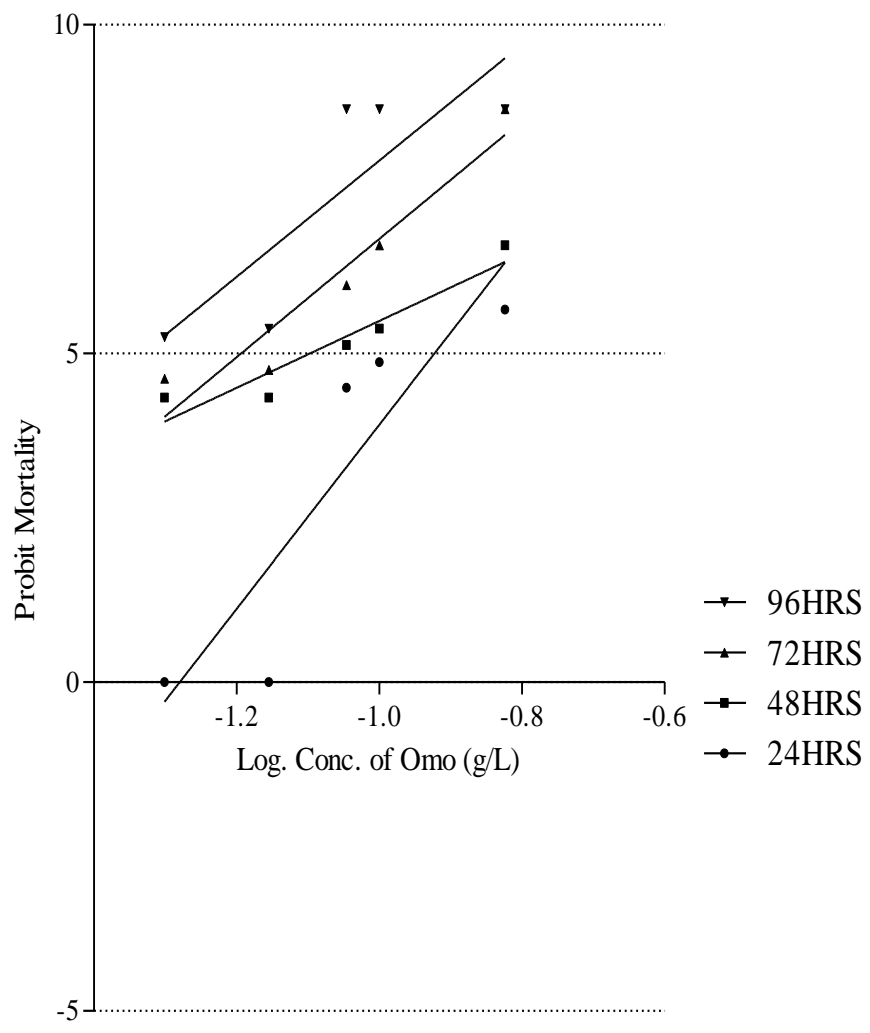

Figure 4.2a: Logarithm Concentration against Probit Mortality of Clarias gariepinus exposed to various acute concentrations of Omo detergent $(\mathrm{g} / \mathrm{L})$ during the hours of exposure.

\section{MEDIAN LETHAL CONCENTRATION}

The median lethal concentration of various acute concentrations of Omo and Ariel exposed to Clarias gariepinus during the 24, 48, 72 and 96 hours exposure period were as represented in Figure 4.2a, (24 hours $\mathrm{LC}_{50}$ was $0.12 \mathrm{~g} / \mathrm{L}$, 48 hours $\mathrm{LC}_{50}$ was $0.07 \mathrm{~g} / \mathrm{L}, 72$ hours $\mathrm{LC}_{50}$ was $0.06 \mathrm{~g} / \mathrm{L}$ and 96 hours $\mathrm{LC}_{50}$ was $0.05 \mathrm{~g} / \mathrm{L}$ ) and Fig $4.2 \mathrm{~b}$ (24 hours $\mathrm{LC}_{50}$ was $0.13 \mathrm{~g} / \mathrm{L}$, 48 hours $\mathrm{LC}_{50}$ was $0.08 \mathrm{~g} / \mathrm{L}, 72$ hours $\mathrm{LC}_{50}$ was $0.07 \mathrm{~g} / \mathrm{L}$ and 96 hours $\mathrm{LC}_{50}$ was $0.06 \mathrm{~g} / \mathrm{L}$ ) respectively.

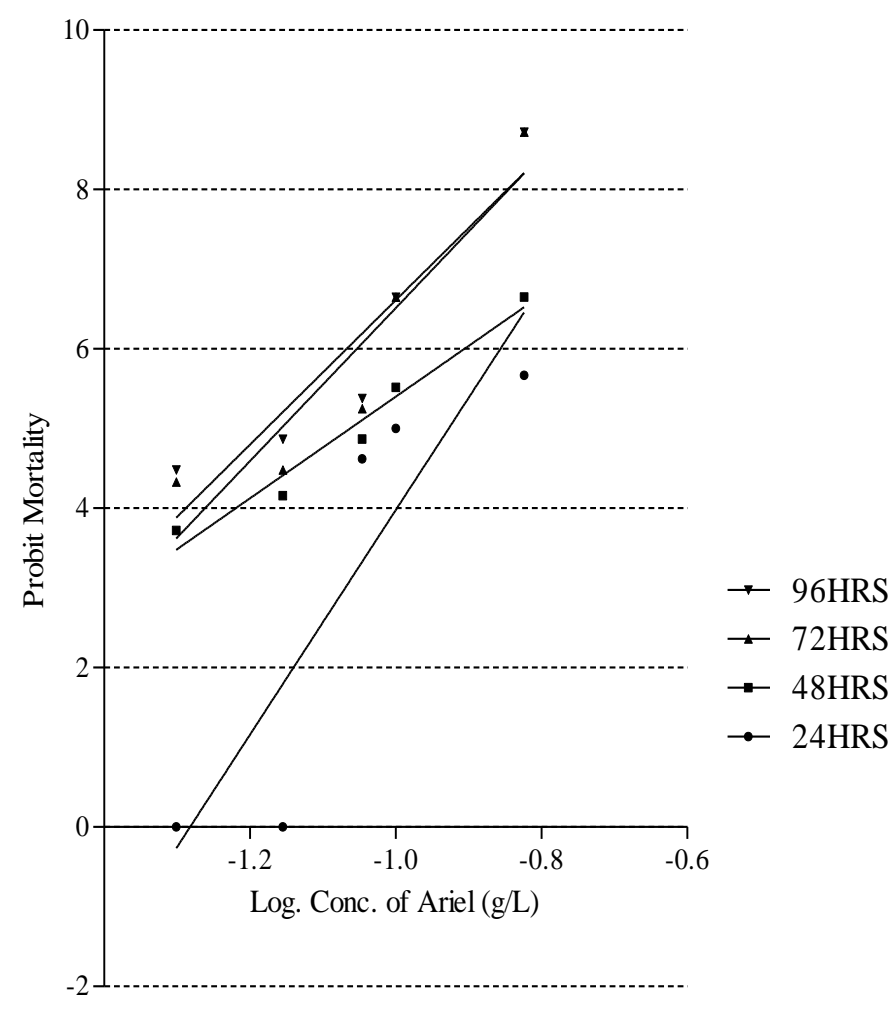

Figure 4.2b: Logarithm Concentration against Probit Mortality of Clarias gariepinus exposed to various acute concentrations of Ariel detergent $(g / L)$ during the hours of exposure.

\section{BEHAVIOURAL RESPONSE}

Behavioural changes such as uncoordinated movements, somersaulting convulsion, excess secretion of mucus, erration swimming and increase in operculum ventilation, respiratory distress, strong spasm, paralysis, sudden quick movement and prior to the death, darkening of fish were observed during the periods of study. The colour of the skin of fish exposed to the test toxicant changed from the normal darkly pigmentation in the dorsal and lateral parts to a pale colour. 
Table 2a: Mean water quality parameters for acute bioassay of Omo on juveniles of the African catfish Clarias gariepinus for 96 hours.

\begin{tabular}{lcccccc}
\hline Parameters & \multicolumn{7}{c}{ Omo concentration (g/L) } \\
\cline { 2 - 7 } & $\mathbf{0 . 0 0}$ & $\mathbf{0 . 0 5}$ & $\mathbf{0 . 0 7}$ & $\mathbf{0 . 0 9}$ & $\mathbf{0 . 1 0}$ & $\mathbf{0 . 1 5}$ \\
\hline Temp. $\left({ }^{\circ} \mathbf{C}\right)$ & $24.00 \pm 0.00$ & $24.00 \pm 0.00$ & $24.00 \pm 0.01$ & $24.00 \pm 0.01$ & $24.00 \pm 0.01$ & $24.00 \pm 0.01$ \\
${ }^{*}$ DO $(\mathbf{m g} / \mathbf{L})$ & $10.24 \pm 0.02$ & $10.04 \pm 0.01$ & $9.32 \pm 0.01$ & $8.97 \pm 0.12$ & $8.91 \pm 0.02$ & $7.76 \pm 0.03$ \\
pH & $6.94 \pm 0.00$ & $7.24 \pm 0.10$ & $7.74 \pm 0.01$ & $8.21 \pm 0.03$ & $8.64 \pm 0.02$ & $9.38 \pm 0.20$ \\
${ }^{\text {\#FCO }}$ & $3.24 \pm 0.00$ & $3.11 \pm 0.01$ & $2.74 \pm 0.02$ & $2.80 \pm 0.01$ & $1.45 \pm 0.02$ & $1.07 \pm 0.02$ \\
${ }^{\circ}$ TAL & $36.45 \pm 0.00$ & $38.95 \pm 0.10$ & $40.75 \pm 0.03$ & $42.32 \pm 0.02$ & $46.23 \pm 0.02$ & $49.45 \pm 0.02$ \\
\hline
\end{tabular}

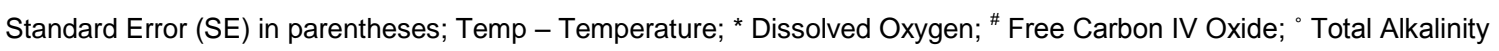

Table 2b: Mean water quality parameters for acute bioassay of Ariel on juveniles of the African catfish Clarias gariepinus for 96 hours.

\begin{tabular}{lcccccc}
\hline Parameters & \multicolumn{7}{c}{ Ariel concentration (g/L) } \\
\cline { 2 - 7 } & $\mathbf{0 . 0 0}$ & $\mathbf{0 . 0 5}$ & $\mathbf{0 . 0 7}$ & $\mathbf{0 . 0 9}$ & $\mathbf{0 . 1 0}$ & $\mathbf{0 . 1 5}$ \\
\hline Temp. $\left({ }^{\circ} \mathbf{C}\right)$ & $24.00 \pm 0.00$ & $24.00 \pm 0.00$ & $24.00 \pm 0.00$ & $24.00 \pm 0.00$ & $24.00 \pm 0.01$ & $24.00 \pm 0.01$ \\
${ }^{*}$ DO $(\mathbf{m g} / \mathbf{L})$ & $10.24 \pm 0.02$ & $10.01 \pm 0.01$ & $9.32 \pm 0.01$ & $9.07 \pm 0.02$ & $8.98 \pm 0.01$ & $8.76 \pm 0.02$ \\
PH & $6.94 \pm 0.00$ & $7.12 \pm 0.01$ & $7.20 \pm 0.01$ & $7.34 \pm 0.01$ & $7.89 \pm 0.02$ & $8.45 \pm 0.02$ \\
"FCO & $3.24 \pm 0.00$ & $3.11 \pm 0.02$ & $2.94 \pm 0.01$ & $2.81 \pm 0.01$ & $2.09 \pm 0.01$ & $1.92 \pm 0.01$ \\
${ }^{\circ}$ TAL & $36.45 \pm 0.00$ & $38.05 \pm 0.02$ & $40.15 \pm 0.01$ & $42.32 \pm 0.01$ & $43.30 \pm 0.02$ & $45.45 \pm 0.02$ \\
\hline
\end{tabular}

Standard Error (SE) in parentheses; Temp - Temperature; * Dissolved Oxygen; \# Free Carbon IV Oxide; ' Total Alkalinity

\section{WATER QUALITY PARAMETERS}

The mean water quality parameters measured during the 96 hours experimental period is as presented in Table $2 \mathrm{a}$ and $\mathrm{b}$. Water quality parameters monitored were seen to have varied with the detergents concentration when compared with the control. The temperatures were observed to have remained almost constant, while the dissolved oxygen values increased. So do alkalinity and $\mathrm{pH}$ the later indicating that the medium changed from being weakly acidic to being strongly alkaline. Conversely, free carbon iv oxide content in the medium was observed to have continuously decreased with increase in toxicant concentration.

\section{DISCUSSION}

Most notable of the behaviour responses is the erratic swimming which indicated that the introduction of the toxicant was a lien to the fish environment and beyond the tolerable limit of the fish. Also indicative of the toxicity of these toxicants were the increase in the mucus secretion and mottled appearance. The observed abnormal behaviour of Clarias gariepinus characterized by the fish skittering to the surface, frenzied swimming, loss of balance and the fish swimming upside down tend to show the feeling of respiratory impairment probably due to the effect of the detergent on the gills. The behavioural changes observed in this experimental setup in similar to those reported by other researchers such as Chindah et al, (2004) in Tilapia guinensis when exposed in chloropyrofos. The respiratory stress observed must have been so severe as not to have been ameliorated by the observed increase in dissolved oxygen content of the water. Plasma the oxygen carrying 'porter' of the blood could have been implicated. Water quality parameters varied with the test concentration. Although dissolved oxygen increased, the change in $\mathrm{pH}$ is believed to have been very inimical. Detergents, increase ammonium uptake by root and where ammonium concentration is high there would be a corresponding increase in mortality rate (Litar and Lehrer, 1978). It can be assumed that any such increase in ventilatory fate will cause increased flow of soluble detergent to the gill surface where it is absorbed hence rapid poisoning and high mortality obtained in this study. Detergents are very widely used in both industrial and domestic premises like soaps and detergents to wash vehicles. The major entry point into water is via sewage works into surface water. They are also used in pesticide formulations and for dispersing oil spills at sea. The degradation of alkylphenol polyethoxylates (non-ionic) can lead to the formation of alkylphenols (particularly nonylphenols), which act as endocrine disruptors. High phosphate detergents such 
as tri-sodium phosphate (TSP) can be purchased at some paint and hardware stores. Regular cleaning with high phosphate detergents has proven to be effective in reducing lead dust. Lead dust accumulates in window wells and around doors or any other high friction surfaces. Detergents can have poisonous effects in all types of aquatic life if they are present in sufficient quantities, and this includes the biodegradable detergents. All detergents destroy the external mucus layers that protect the fish from bacteria and parasites; plus they can cause severe damage to the gills. Most fish will die when detergent concentrations approach 15 parts per million. Detergent concentrations as low as 5 ppm will kill fish eggs Surfactant detergents are implicated in decreasing the breeding ability of aquatic organisms. Detergents also add another problem for aquatic life by lowering the surface tension of the water. Organic chemicals such as pesticides and phenols are then much more easily absorbed by the fish.

A detergent concentration of only 2 ppm can cause fish to absorb double the amount of chemicals they would normally absorb, although that concentration itself is not high enough to affect fish directly. Phosphates in detergents can lead to freshwater algal blooms that release toxins and deplete oxygen in waterways. When the algae decompose, they use up the oxygen available for aquatic life. The main contributors to the toxicity of detergents were the sodium silicate solution and the surfactants-with the remainder of the components contributing very little to detergent toxicity. The potential for acute aquatic toxic effects due to the release of secondary or tertiary sewage effluents containing the breakdown products of laundry detergents may frequently be low. However, untreated or primary treated effluents containing detergents may pose a problem. Chronic and/or other sublethal effects that were not examined in this study may also pose a problem.

The high mortality rate of fish at $100 \%$ concentration of the detergent tends to indicate that the higher the concentration, the higher the mortality at a given time revealing that the Omo detergent is most toxic of the two used in this study. The acute toxicity test of detergents on the African catfish Clarias gariepinus is dose dependent; as the concentration of detergents increased the rate of mortality Clarias gariepinus also increased which is directly proportional. At high concentrations of the detergents, the survival rate of the fish decreases significantly $(P<0.05)$. For The values of median lethal concentrations obtained in this study makes this products highly lethal for the test fish with Omo detergent most lethal of the two detergents used for the bioassay as supported by the study of OkoliAnunobi et al. (2002) when the Nile tilapia was exposed to acute concentrations of Elephant detergent. Aguigwo (1998), Fafoye et al., (2004), and Chindah et al., (2004) reported MLC of $50.12 \mathrm{mg} / \mathrm{L}, 3.4$ and $3.2 \mathrm{ppm}$ and
$0.002 \mathrm{mg} / \mathrm{L}$ when Heteroclarias, and Tilapia guinensis were exposed to various concentrations of cassava mill effluent, Parkia biglobosa and Raphia vinifera and Chloropy rios respectively. Detergents are known to damage olfactory epithelium in the nasal capsule , inhibit enzyme activity (Drewa et al. 1979) and cause oxygen stress by affecting the gills (Okwuosa and Omoregie, 1995).Notwithstanding the limited information that is available, certain facts can be derived. A study by Chio et al., (1992) showed that the per capita usage of detergents in the Philippines in 1989 is at 2.5 to $3.4 \mathrm{~kg} /$ year. This knowledge brings to light the possible environmental hazard that detergent may present to our receiving aquatic ecosystems. In the absence of an efficient wastewater treatment facility, which is typical of the conditions in developing countries such as Nigeria, there is an urgent need to establish the appropriate infrastructure and water quality management system to protect our water resources. Efforts must be directed at developing standardized toxicity test procedures for determining the potential hazards caused by detergents and other substances. In line with this effort, the present study proposes the above-mentioned toxicity test procedure as a tool for monitoring purposes.

\section{CONCLUSION}

This study has revealed that detergent can be acutely toxic to the test fish Clarias gariepinus caution therefore, needs to be taken when employing the use of the detergents in water bodies. The effect of the detergents on the test media was to shoot the media's $\mathrm{pH}$ to the alkaline death point. Death could therefore have occurred either by direct poisoning or indirectly by making the media unconductive or even by both; whichever is the case, the source for the cause of death was the detergent.

\section{RECOMMENDATION}

In as much as this study is geared towards the establishing of the toxicity of certain common household products to local fish or other species in local environmental conditions, it is recommended that: Chronic toxicity test be done to firmly establish and document the toxicity of the two brand of detergents on Clarias gariepinus The test procedure and experimental design be extended to include a wider range of detergents and other possible toxicants, especially those that are widely used, and whose effects are not yet documented. Toxicity tests also can be done on the specific components of such detergents, taking into account possible additive, synergistic, antagonistic or 
036 E3 J. Sci. Res.

inhibitive action of the other local fish species, in order to contribute to the standardization of fish toxicity test in the country.

\section{REFERENCES}

Aguigwo JN (1998). Studies of Acute toxicity of cassava leaf extracts on the African catfish Clarias angullaris. Journal of Aquatic Sciences. 13: 29-32.

Ajao EA (1990). The influence of domestic and industrial effluents on populations of sessile and benthic organism in lagos lagoon. Ph.D thesis University of Ibadan.

APHA (1989). American Public Health Association: Standard Method for examination of water and waste water. American Public Health Association Washington DC 1268p.

Chindah AC, Sikoki FO, Vincent-Akpa I (2004). Toxicity of an organophosphate pesticide (Chloropyrifos) on a common Niger Delta Wetland fish. Tilapia guinensis. (Blacker, 1862). J. Appl. Sci. Environ mgt. 8(2): 11-17.

Chio JT, Kua ET, Dayrit, FM (1992). Philippines J.Sci.1-15

Ezemonye LIN, Ogeleka, DF, Okieimen FE (1997).Acute toxicity of industrial detergent (Neatex) and corrosion inhibitor (Norust CR486) on the cichlids: Tilapia guineensis. Chemistry and Ecology 23(2):

Fafoye OO, Adebisi AA, Fagada SO (2004). Toxicity of parkia biglobosa and Raphia Vinifera extracts on Clarias gariepinus Juveniles. African Journal of Biotechnology 3(11): 627-630.

Imonite I.C (1994): Studies on the acute toxicity and rate of loss of biological action of household detergent tested against Clibaneriani africanus M.Sc thesis, University of Lagos.
Ita EO (1980). A Review of Recent Advance in warm water Aquaculture Resource and A proposed Experimental Design for maximizing fish production in Nigeria. K. L. R. I Tech. Rep. Series, 51: 30p.

Okoli-Anunobi CIAN, Ufodike EBC, Chude LA (2002). Lethal effects of the detergent, elephant blue on the Nile tilapia, Oreochromis niloticus (L), J. Aquatic Sci. 17 (2): 95 - 97

Oti EE (2002). Acute toxicity of cassava mill, effluent to the African catfish hybrid. Journal of Aquatic Science: 17(1): 31-34.

Tovell WPA, Newsome C, Howes D (1974). Effects of water hardness on the toxicity of an anionic detergent to fish. Water Research 8: 291-296

Warner RE (1962). Research direct towards development of test procedures for evaluating allowable limits of concentrations of toxic substances in the aquatic environment. Final report, USPHS contract No. pH 66-62-55, 30, November, 1962, 1-56pp 